Making the epidemic more visible, and understanding its dynamics through such reports is important not only in managing the impact of the epidemic but also in eventually being able to turn the tide of it. For all spheres of planning, it is essential to have an understanding of where the country stands in terms of HIV/AIDS.
For further information contact:

Professor Rob Dorrington, UCT Centre for Actuarial Research

Tel. (021) 650-2467

Dr Debbie Bradshaw, MRC Burden of Disease Research Unit

Cell: 0824611234

\title{
AWARDS
}

\section{South African researchers awarded R220 million research grant}

The United States National Institutes for Health has announced the award of a major research grant to leading South African AIDS researchers. The $\$ 21.3$ million labout R220 million) award over 5 years will support HIVIAIDS research in a family setting, a rarely tried approach to fighting the disease. This grant is the largest yet made by the Comprehensive International Program for Research on AIDS (CIPRA). This national collaborative research effort will be led by Professor James McIntyre and co-ordinated by the Perinatal HIV Research Unit of the University of the Witwatersrand.

'Low-income households in South Africa carry the greatest burden of HIV/AIDS, experience the greatest negative effects, and have the least reserves to cope,' says Professor McIntyre. The new CIPRA grant, 'Safeguarding the Household: Comprehensive AIDS Research', will address HIV/AIDS as a problem not simply of individuals but of entire families, he explains, and all family members may participate in the studies. The cutting-edge research programme will focus on aspects of HIV treatment in adults and children, tuberculosis and affordable laboratory tests.

'This research agenda is of crucial importance to South Africa and our region. It will gather essential information for the government's AIDS programmes in the future, and covers many of the key areas raised in the recent cabinet statement on AIDS; explains Professor McIntyre. 'The grant award recognises the quality of South African AIDS research and will provide the opportunity to develop many more local researchers through an extensive, linked, training programme.'

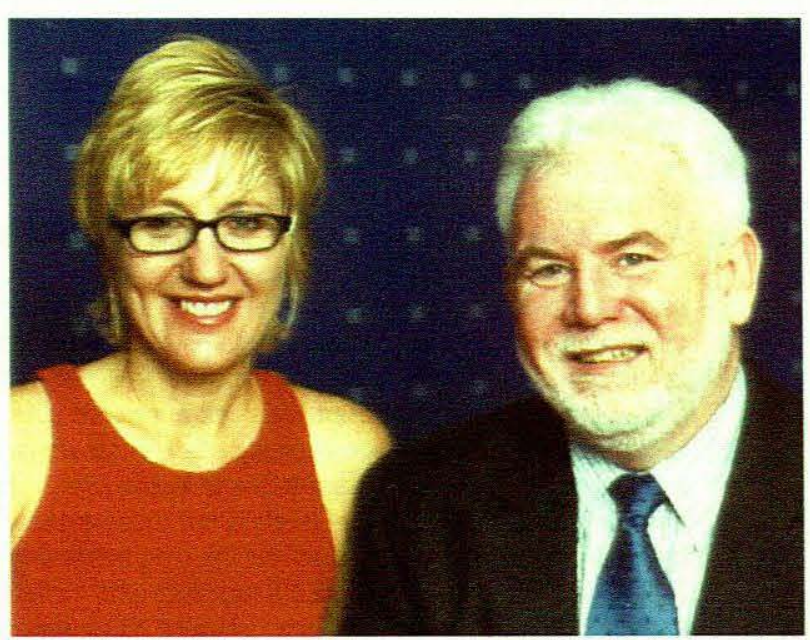

Professor James McIntyre and Glenda Gray, Executive Directors of the Perinatal HIV Research Unit, Chris Hani Baragwanath Hospital, Soweto.

The project will:

- Evaluate an affordable HIV/AIDS treatment programme for adults and children in a family setting at primary care level.

Test whether treatment interruption is an affordable and feasible way of controlling HIV infection in children that reduces the progression to AIDS.

Determine the efficacy of two standard childhood vaccines (used to prevent pneumonia and meningitis) in preventing AIDS-related complications in infants.

- Evaluate the community effect of highly active antiretroviral therapy on sickness and deaths due to AIDS and tuberculosis.

Develop simple, inexpensive methods of diagnosing HIV and monitoring treatment and drug resistance. 